\title{
IDENTIDADES DE GÉNERO Y CULTURAS POLÍTICAS EN LA SEGUNDA REPÚBLICA*
}

\author{
Ana Aguado
}

\section{Las culturas políticas en clave de género}

La relación histórica entre los conceptos de culturas políticas, ciudadanía femenina e identidades de género ha generado sugerentes reflexiones en los debates de la historiografía europea de los últimos años. Concretamente, el estudio de las experiencias, estrategias y alternativas desarrolladas por las mujeres como ciudadanas -o como excluidas de la ciudadanía- a lo largo de la historia contemporánea, tanto en la esfera pública y en el ámbito de «lo político», como en la esfera privada, en la vida cotidiana, y en las diversas formas de sociabilidad y de prácticas cívicas de vida.

La reflexión en torno al concepto histórico de «culturas políticas» ${ }^{1}$ y su relación con la ciudadanía femenina y la construcción de las identidades de género puede estructurarse a partir de tres ejes: la experiencia social que las mujeres han acumulado en las respectivas culturas políticas, los discursos que estas culturas han desarrollado o posibilitado desarrollar sobre las mismas, y el horizonte utópico presente en los diferentes proyectos políticos que impregna los dos planos anteriores: el de las formulaciones teóricas y el de las realidades cotidianas ${ }^{2}$.

Desde estas perspectivas, el estudio del desarrollo del pensamiento igualitario, de las acciones colectivas y de los feminismos, en tanto que movimientos sociales, debe incorporar análisis relativos a la relación entre cultura

\footnotetext{
* Este trabajo participa del Proyecto de Investigación I+D+I 149/05.

1. BAKER, K. M., «El concepto de cultura política en la reciente historiografía sobre la Revolución francesa», Ayer. Más allá de la historia social, nº 62 (2006), pp. 89-110.

2. NASH, Mary, Mujeres en el mundo. Historia, retos y movimientos, Madrid, 2004.
} 
política ${ }^{3}$, cultura de género y desarrollo del movimiento de mujeres en la España contemporánea, sumando elementos explicativos a las interpretaciones hoy ya convertidas en clásicas de la historiografía especializada que vinculan feminismo prioritariamente con sufragismo. La reapropiación por parte de las mujeres de los significados discursivos existentes en las culturas políticas de las que formaban parte -liberales, republicanas, socialistas- no sólo les permitió representarse como susceptibles de acceder a las ventajas de la igualdad y de la libertad, sino también construir, redefinir, a partir de su propia identidad y de sus propias experiencias, un nuevo orden simbólico, autorreferencial ${ }^{4}$.

Fueron los discursos igualitarios presentes en los lenguajes políticos de clase y de izquierda, los que permitieron, desde su reapropiación o «relectura» hecha por las mujeres pertenecientes a las culturas republicanas y obreras, articular desde ellos sus intereses, dar significado a sus acciones y construir su identidad como agentes sociales 5 . Así, el desarrollo de una conciencia femenina/feminista en las culturas políticas de izquierda, fue generando, en la España de comienzos del siglo XX, en los años veinte y treinta, estrategias diversas, no unívocas, frente a la falta de derechos de las mujeres. En su condición de posibilidad, actuaron tanto los lenguajes políticos igualitarios como los vínculos personales y familiares, de tal manera que puede decirse que lo político se convertía en personal. Y lo hacía como resultado de la interrelación entre contexto social e interiorización de los significados de lo que fue inicialmente el discurso universalista ilustrado -las categorías de individuo, igualdad, ciudadanía, derechos humanos-. Fue la recepción de ese mismo discurso político y, a la vez, de sus componentes de exclusión de la esfera pública y subordinación de las mujeres, lo que hizo que las mujeres comenzaran a concebirse con una identidad como tales, y como sujetos de derechos. Podemos decir, en este sentido, que el discurso universalista engendró paradójicamente, las nuevas «identidades femeninas», engendró las demandas de ciudadanía para las mujeres, y engendró en este sentido, el desarrollo de los feminismos.

La posesión de estos lenguajes, que eran por un lado igualitarios, pero que por otro lado eran identitarios -es decir, habían construido ya un «nosotras»

3. Almond, G.A. y Verba, S., The Civic Culture revisited, Londres, 1989.

4. Scott, Joan, «El eco de la fantasía: la historia y la construcción de la identidad», Ayer. Más allá de la historia social, no 62 (2006), pp. 111-138.

5. NASH, Mary, «Experiencia y aprendizaje: la formación histórica de los feminismos en España», Historia Social, no 20 (1994), pp. 151-172 y SÁNCHEZ MuÑOZ, C., «Genealogía de la vindicación», en BELTRÁN, E. y otras, Feminismos. Debates teóricos contemporáneos, Madrid, 2001, pp. 17-73. 
en plural-, permitieron a las mujeres vinculadas a las culturas políticas republicanas y socialistas desarrollar formas de actuación y prácticas específicas, en lo público y en lo privado, y dotarlas de un significado político transformador. Y a la vez, estas prácticas, estos significados, fueron los que, en última instancia, permitieron a estas mujeres articular progresivamente nuevas demandas y formas organizativas autónomas.

\section{Construyendo la igualdad desde el republicanismo}

Desde el cambio del siglo y comienzos del siglo XX, puede verse cómo, desde la herencia cultural feminista laicista y republicana, la «segunda generación» de mujeres librepensadoras y laicistas -magníficamente estudiadas por $\mathrm{M}^{\mathrm{a}}$ Dolores Ramos ${ }^{6}$ y Luz Sanfeliu ${ }^{7}$, desarrolló prácticas sociales específicas, de género, dentro de la cultura política del republicanismo laico y radical. En el caso específico de Valencia, dentro de la cultura política blasquista, en espacios públicos y privados, de ocio, de lectura, centros de reunión, casinos, fiestas, manifestaciones. Es decir, formas diversas del «rumor de lo cotidiano» ${ }^{8}$.

Estas republicanas enlazaron en los años veinte con las mujeres $-y$ las organizaciones- sufragistas, muchas de ellas antiguas librepensadoras, masonas y republicanas, y otras socialistas. Fue a partir de estas fechas, y en concreto en el marco de la Primera Guerra Mundial en Europa y sus repercusiones en cuanto al debate sufragista, cuando se fundó en Valencia la revista Redención -que se presentaba en su cabecera como «revista feminista»-. Igualmente, la Sociedad Concepción Arenal, con planteamientos y objetivos ya claramente políticos, de carácter sufragista. Fue también, en torno al empuje producido en el contexto bélico, cuando en 1918 se creó en Valencia la Liga Española para el Progreso de la Mujer, que nacía no como una sociedad local sino como coordinación de diferentes grupos en toda España. Y este sufragismo se plasmaría y concretaría políticamente durante los años treinta en la Segunda República.

El sufragio femenino conseguido en las Cortes Constituyentes de la Segunda República no puede ser explicado como algo gratuito o casual, sino

6. RAmos, Mª Dolores, «La república de las librepensadoras (1890-1914): laicismo, emancipismo, clericalismo», Ayer. República y republicanas en España, $\mathrm{n}^{\circ} 60$ (2005), pp. 45-74.

7. SANFELIU, Luz, Republicanas. Identidades de género en el blasquismo (1895-1910), Valencia, 2005. Igualmente: SANFELIU, Luz, «Familias republicanas e identidades femeninas en el blasquismo, 1896-1910», Ayer. República y republicanas en España, nº 60 (2005), pp. 75-103.

8. CASTELlS, Luis (ed.), El rumor de lo cotidiano. Estudios sobre el País Vasco contemporáneo, Bilbao, 1999. 
como resultado de toda una génesis y tradición anterior, heterogénea en sus alternativas políticas, y a la vez muy influyente ideológica y culturalmente ${ }^{9}$. Sólo se explica históricamente partiendo, por un lado, de esta progresiva conformación de identidades de género y de clase, tanto en las mujeres de las clases populares como en las mujeres de las minorías ilustradas y cultas. Y partiendo, por otro lado, de una diversa y heterogénea presencia del pensamiento igualitario en las diferentes culturas políticas. De la existencia desde finales del siglo XIX y primeras décadas del XX de una genealogía femenina, de mujeres con prácticas políticas, experiencias, discursos y formas de conciencia. Son estos elementos presentes en el mundo de lo «político» los que pueden explicar la transformación y el punto de inflexión que representó el nuevo contexto histórico de la Segunda República, y la legislación desarrollada por ella.

La especificidad del período republicano implica tanto continuidades como cambios respecto a las relaciones de género en los espacios privados y públicos, y en este sentido, requiere un análisis sobre en qué medida las prácticas sociales y las identidades culturales de feminidad y masculinidad comenzaron a transformarse por las posibilidades políticas, legislativas y culturales abiertas en el breve contexto republicano; pero también, en qué medida y con qué límites estos cambios legislativos iban a afectar a la vida cotidiana de las mujeres de diferentes sectores sociales. En este sentido, la Segunda República significó, fundamentalmente, la consecución de la ciudadanía política y social para las mujeres, del sufragio y de derechos y libertades individuales; pero también, en un sentido más amplio, el desarrollo de una importante labor legislativa que iba a posibilitar como condición «necesaria»-aunque no «suficiente»-cambios reales en la vida privada y pública tanto de las mujeres como de los hombres, pues ésta se vio afectada -en mayor o menor medida- por la introducción de cambios tan concretos y significativos como la escuela mixta, el matrimonio civil, el divorcio, el progresivo desarrollo de una legislación laboral igualitaria o el sufragio femenino ${ }^{10}$.

9. RAMOS, $M^{a}$ Dolores, «Cambio social y feminismo en la España del siglo XXI (o nuestra realidad, ayer y hoy)», en Los desafíos del feminismo en el siglo XXI, Sevilla, 2000, p. 117 y ESPIGADO, Gloria, «Mujeres y feminismo en Andalucía: la formación de una conciencia emancipista», en Actas del III Congreso de Historia de Andalucía, Córdoba, 2002, pp. 47-64.

10. Los trabajos pioneros que se publicaron en España en torno a la situación social de las mujeres, el sufragismo y a la evolución del feminismo en España fueron los de FAGOAGA, Concha, La voz y el voto de las mujeres. El sufragismo en España, 1877-1931, Barcelona, 1985; SCANLON, Geraldine M., La polémica feminista en la España contemporánea (1868-1974), Barcelona, 1986 y CAPEL, Rosa, El trabajo y la educación de la 
En este contexto, a partir de 1931 las mujeres, tanto de derechas como de izquierdas, experimentaron un importante proceso de politización, de participación en «lo público», y de ejercicio de la ciudadanía. Con la Segunda República y con la consecución del sufragio y de los derechos políticos, se inicia una nueva etapa cualitativamente distinta a las anteriores, porque por primera vez se puede hablar de democratización del sistema político, entre otras razones, porque por vez primera la mitad de la población, las mujeres, se convierten en ciudadanas, se incorporan a la ciudadanía política ${ }^{11}$. Pero hizo falta una larga génesis, y un tránsito generacional, para que se consolidara en la sociedad española una concepción de la ciudadanía que incluyese social y políticamente a las mujeres. Puede decirse así, en sentido estricto, que la cultura política desarrollada por las mujeres de procedencia ideológica republicana y socialista ejerció un importante papel modernizador y democratizador, que se haría realidad en la configuración del Estado en el nuevo contexto republicano.

La labor legislativa republicana iba a posibilitar, como condición necesaria aunque no siempre suficiente, cambios importantes respecto a la consecución de la ciudadanía política y social para las mujeres, y en este sentido, fue un punto de inflexión. Pero lo fue sobre todo porque representó un momento especialmente significativo de construcción discursiva de las identidades de género, un momento en el que se desarrollaron unas prácticas políticas femeninas a partir de la apelación general al igualitarismo republicano, para que incluyese a un sujeto colectivo, «las mujeres», pues se había construido anteriormente excluyéndolas, a través del discurso de la diferencia sexual del mismo liberalismo. Pero para conseguir esa inclusión, los feminismos sufragistas e igualitaristas herederos de la misma Ilustración debían actuar en nombre de «las mujeres», y de este modo, apelaban a la diferencia, y ahí radicaría una de las paradojas generadas por las culturas feministas a lo largo del siglo XX.

Así, la Segunda República posibilitó la presencia en la vida pública y política de una primera generación de mujeres -la primera generación de

mujer en España. 1900-1930, Madrid, 1982. Posteriormente AgUADO, Ana y RAMOS, Ma Dolores, La modernización de España. Cultura y vida cotidiana (1917-1939), Madrid, 2002 y AGUADO, Ana, «Entre lo público y lo privado: sufragio y divorcio en la Segunda República», Ayer, no 60 (2006), pp. 105-134.

11. BUSSY GENEVOIS, Danièle, «Historia de una mayoría ciudadana. Ciudadanía femenina y Segunda República», en AGUADO, Ana, Las mujeres entre la historia y la sociedad contemporánea, Valencia, 1999, pp. 33-64. También de la misma autora: BUSSY GENEVOIS, Daniéle, "Citoyennes de la Seconde République», en BARRACHINA, Marie-Aline; BuSSY GENEVOIS, Danièle y YusTA, Mercedes, Femmes et Démocratie. Les Espagnoles dans l'espace public (1868-1978), Nantes, 2007, pp. 129-145. 
universitarias desde que se legalizó la presencia femenina en la Universidad en 1910-, caracterizada por su modernidad, feminismo, y preparación cultural e intelectual, aunque éstas fuesen, por supuesto, un grupo minoritario. $\mathrm{Y}$ en tercer lugar, el contexto republicano posibilitó paralelamente la incorporación por vez primera de miles de mujeres a organizaciones políticas específicamente femeninas, más allá de las reducidas asociaciones de los años veinte como la ANME o la UME. En definitiva, el ejercicio de la ciudadanía. La República iba a ser, entre otras muchas de sus características, la República de las ciudadanas. Así lo analizaría María Lejárraga -quien como es sabido se hacía llamar María Martínez Sierra asumiendo el apellido de su marido-, diputada socialista en las Cortes de 1933, en el libro La mujer española ante la República publicado en 1931, en el que demandaba la implicación y el apoyo de las mujeres al nuevo régimen:

«Mujeres ambiciosas, el gobierno de la Buena Voluntad Española os puede dar puestos y responsabilidad. Mujeres generosas, el gobierno de la República os puede dar deberes. Mujeres justas, la República os puede dar derechos. ¡Puede, sabe, quiere y le conviene! ${ }^{12}$

Desde las primeras décadas del siglo XX, la presencia de las mujeres en la esfera pública -en la cultura política para Habermas- era, en efecto, cada vez más visible. Particularmente, la de las mujeres republicanas y laicistas ${ }^{13}$. Pero, paralelamente, el discurso republicano hegemónico y clásico contenía en sus planteamientos límites muy significativos a la igualdad entre mujeres y hombres. Entre ellos, una prevención histórica ante la libertad y la autonomía femeninas, que era justificada por la tradicional vinculación de las mujeres con la religión y con la Iglesia; frente a ella, los republicanos mantenían una larga pugna por la influencia sobre esta clientela femenina. Pero esta prevención estaba basada en cuestiones más profundas: en la ancestral misoginia patriarcal, y en sus discursos y mecanismos de control social, de los cuales no estaban exentos, ni mucho menos, los republicanos ${ }^{14}$. Y la interrelación entre estos dos aspectos «contradictorios» es la que nos interesa explicar, más allá de los tópicos simplificadores, para analizar así en qué medida sus repercusiones so-

12. MARTínez Sierra, María, La mujer española ante la República, Madrid, 1931.

13. SANFELIU, Luz, Republicanas...

14. DUARTE, Ángel, «La esperanza republicana», en CRUZ, Rafael y PÉREZ LedESMA, Manuel (eds.), Cultura y movilización en la España contemporánea, Madrid, 1997, pp. 169-199 y SAlOMÓn CHÉliz, Pilar, «Beatas sojuzgadas por el clero: la imagen de las mujeres en el discurso anticlerical de la España del primer tercio del siglo XX», Feminismo/s, $\mathrm{n}^{\circ} 2$ (2003), pp. 41-58. 
bre la vida pública y privada iban a afectar, también de forma contradictoria, a las mujeres de diferentes grupos sociales y pertenencias ideológicas.

Junto con la consecución de la ciudadanía femenina con la Constitución de 1931, el triunfo de la ideología y el contexto político republicano significó, además, la condición de posibilidad para el desarrollo de una conciencia femenina, y por tanto, de una específica identidad de género. Una conciencia y una identidad que se fue construyendo históricamente, desde un determinado momento, a partir de la hegemonía de la cultura política republicana que extendía y generalizaba los significados discursivos igualitaristas heredados de la Revolución Francesa y de la Ilustración.

Por ello la República fue un momento de inflexión fundamental, no tanto, o no sólo, por los cambios introducidos en el estatus político, legal, social o educativo de las mujeres, en la ciudadanía de éstas, y cómo estos cambios afectaron a sus posibilidades de emancipación o igualdad -esta es la pregunta más evidente-; sino sobre todo, cómo esos cambios alteraron el significado del término «mujeres», la existencia de una determinada identidad de género, o la percepción de las mujeres de la misma. Esta es la pregunta menos evidente, y la que sin embargo es especialmente relevante para la historización de las categorías que el presente toma como realidades evidentes por sí mismas ${ }^{15}$.

Desde los inicios de la contemporaneidad el espacio público/político se había constituido en clave masculina, y esta era la forma en que los sujetos masculinos habían accedido a una subjetividad individual y autónoma. En España, a partir de 1931, sería posible para las mujeres, real y simbólicamente, la consolidación de esa individualidad, como resultado de la concreción de la cultura política republicana en derechos de ciudadanía. Pero también, al mismo tiempo, fue posible en este contexto la consolidación de una identidad de género, de «mujeres» como sujeto, porque en la concepción republicana -como ha señalado Habermas- la política misma constituía un medio a través del cual los miembros de «comunidades solidarias» se hacían conscientes de sus recíprocas demandas, a través de relaciones de reconocimiento mutuo ${ }^{16}$. Y fue en el contexto político y cultural republicano cuando las mujeres tuvieron esta posibilidad. Así, lo que va a cambiar a lo largo del tiempo no es simplemente la percepción que se tiene de una identidad, sino la identidad misma. Y la cultura política republicana -especialmente a partir del momento en que se tradujo en ley-, abrió la «caja de Pandora»-al igual que la Ilustración en Francia- que ya no podría cerrarse respecto a las demandas de igualdad, de

15. SCOTT, Joan: «El eco de la fantasía...», p. 114.

16. HABERMAS, Jünger, «Tres modelos de democracia. Sobre el concepto de una política deliberativa», Debats, no 39 (1992), p. 18. 
libertad, de razón, también para las mujeres, que se fueron construyendo como tales, como «mujeres», a partir y desde el discurso universalista republicano, en una relación paradójica y contradictoria a veces con el mismo.

La consecución del sufragio femenino en 1931 impulsó la creación de secciones femeninas, tanto en los partidos republicanos y de izquierdas como en los conservadores y de derechas (como en el caso de Acción Popular, posteriormente CEDA), y la incorporación de las mujeres a los mismos. A pesar de que esta incorporación significase en muchas ocasiones la subordinación a las directrices políticas masculinas y su marginación respecto a las decisiones estratégicas importantes ${ }^{17}$. Los partidos conservadores y de derechas se apresuraron a preparar y a organizar a las mujeres en defensa de la religión y de los valores conservadores, desde su relación contradictoria y paradójica con el sufragio y la actuación ciudadana femenina. Los partidos republicanos comenzarían a reaccionar tarde y lentamente ante esta movilización, de tal manera que en 1932 el Partido Radical denunció la poca preocupación de los republicanos en lo relativo a la preparación del electorado femenino ${ }^{18}$.

De forma excepcional y minoritaria, en los grandes partidos republicanos militaron destacadas intelectuales y feministas. Entre ellas, Clara Campoamor en el Partido Radical; Victoria Kent, Catalina Salmerón, Carmen de Burgos o Benita Asas Manterota en el Partido Republicano Radical Socialista -luego escindido entre Izquierda Republicana y Unión Republicana-, o Belén Sárraga en el Partido Republicano Federal. Fue también en la Segunda República cuando por primera vez, a partir de la nueva situación política, surgieron dos grandes organizaciones femeninas de masas, diferenciadas tanto cuantitativa como cualitativamente de las minoritarias organizaciones de las décadas anteriores. Dos grandes organizaciones que iban a movilizar por primera vez a miles de mujeres durante la década, y particularmente durante la guerra, más allá de los grupos minoritarios y elitistas de los años anteriores: por un lado, la Asociación de Mujeres Antifascistas (AMA), creada a partir del grupo Mujeres contra la Guerra y el Fascismo, que comenzó a actuar en 1933; y por otro lado, Mujeres Libres, fundada en 1936 por Lucía Sánchez Saornil, Amparo Poch y Gascón y Mercedes Comaposada ${ }^{19}$.

Con todo, las mujeres que militaron en los partidos republicanos continuaron siendo una minoría, y paralelamente, las actitudes y valoración

17. NÚÑEZ PÉREZ, $M^{a}$ Gloria, «Mujer y partidos republicanos en España (1931-1936)», Cuadernos Republicanos, $\mathrm{n}^{\circ} 11$ (1992), pp. 25-37.

18. IlLION, Régine, «Trabajadoras, sindicalistas y políticas.Zaragoza 1931-1936», Ayer, nº 60 (2006), pp. 135-163.

19. NASH, Mary, Rojas. Las mujeres republicanas en la guerra civil, Madrid, 1999. 
existentes en el seno de estos partidos respecto a las mujeres continuaron siendo androcéntricas y antifeministas. Así se evidenció en los debates parlamentarios sobre el sufragio femenino, donde la conocida postura antisufragista y antifeminista de la práctica totalidad de los diputados republicanos -contrarios a la incorporación de la ciudadanía política para las mujeres-, se debió no sólo a razones estratégicas, de conveniencia u oportunidad política. Se debió igualmente a razones ideológicas, vinculadas con el tradicional discurso misógino y antifeminista liberal. Razones que buscaban su legitimación en el discurso científico «moderno» sobre la mujer, inmerso desde mucho tiempo atrás en unas coordenadas androcéntricas, presentes tanto en el pensamiento liberal como en la tradición conservadora y reaccionaria ${ }^{20}$. Presentes en la «misoginia romántica» en una línea de continuidad cultural que desde el siglo XIX llegaba a los años veinte y treinta del siglo XX y su «vanguardia cultural $»^{21}$.

Esta misoginia, presentada bajo el ropaje de un argumentarlo político, fue la que realmente comportaría el que Clara Campoamor fuera marginada en su propio partido después del debate parlamentario sobre el sufragio. En su libro El voto femenino y yo. Mi pecado mortal, Campoamor comentaba críticamente la resistencia de los hombres republicanos a incorporar a sus partidos a las mujeres, y cómo en muchas ocasiones a las mujeres que militaban se las miraba con desdén o se las condenaba a la inactividad ${ }^{22}$. En el mismo sentido, otras republicanas como Guillermina Medrano, la primera mujer concejal del Ayuntamiento de Valencia por Izquierda Republicana, recordaba cómo el propio Azaña la miró indolente cuando le fue presentada, y cómo rápidamente le volvió la espalda para conversar con otros «políticos» relevantes.

\section{Cultura política e identidad de género en la Segunda República: las republicanas blasquistas valencianas}

A pesar de estas actitudes presentes en la cultura política republicana, paralelamente, el activismo de las mujeres valencianas en la Segunda República muestra las formas mediante las cuales las organizaciones femeninas, surgidas dentro de los partidos políticos republicanos, fomentaron la participación

20. Ortega LóPEZ, Teresa María, «Conservadurismo, catolicismo y antifeminismo: la mujer en los discursos del autoritarismo y el fascismo (1914-1936)», Ayer, $\mathrm{n}^{\circ} 71$ (2008), pp. 53-83.

21. AguAdo, Ana, «La experiencia republicana. Entre la cultura del reformismo político y las culturas obreras» en AGUADO, Ana y RAmos, M ${ }^{a}$ Dolores, La modernización de España...

22. CAMPOAmor, Clara, El voto femenino y yo. Mi pecado mortal, Barcelona, 1981, p. 295. 
de las mujeres en el espacio público y en la vida política. En segundo lugar, muestra cómo el aprendizaje de la autonomía, a partir de los discursos autolegitimadores, que representaron estas prácticas políticas, contribuyó a neutralizar el modelo de feminidad doméstica dominante en una sociedad en la que el espacio público continuaba siendo hegemónicamente masculino. Así, aunque la pervivencia de la apelación a un discurso diferenciador era frecuente en las mujeres republicanas, hay paralelamente una reclamación de igualdad entre mujeres y hombres a partir de argumentos específicamente feministas. Y también, muestra, en tercer lugar, cómo la aparición de «secciones» de mujeres y de un activismo político femenino dentro de la vida y de la actividad política de los partidos durante la República sirvió a la vez como instrumento de captación de un electorado femenino, al que por primera vez los partidos miraban con interés político por su nueva condición de votantes. Un ejemplo representativo de todo esto es el de las mujeres republicanas del Partido de Unión Republicana Autonomista -el PURA-, el partido de Vicente Blasco Ibáñez $z^{23}$.

Las mujeres republicanas habían estado formando parte activa de la cultura política blasquista ${ }^{24}$, y en los años treinta el partido aprovecharía estos antecedentes. Con el advenimiento de la Segunda República, el blasquismo consiguió recoger toda esta tradición asociacionista femenina, sus principios y actividades. Pero a diferencia de períodos anteriores, en el que las mujeres formaban parte del universo social, familiar y cultural republicano pero no pertenecían a la estructura interna del partido, durante la República el PURA desarrollaría una estrategia de organización política de las mujeres desde su proyecto político modernizador y laicista, creando las Agrupaciones Femeninas Republicanas ${ }^{25}$.

A pesar de que en el debate parlamentario sobre el sufragio femenino los partidos republicanos se opusieron al mismo por razones estratégicas, las mujeres blasquistas de Valencia fueron absolutamente favorables al voto, como se recoge en los artículos publicados por figuras como la de Amalia Carvia en El Pueblo, el periódico blasquista, durante esos años. Por ejemplo:

«La concesión del voto a la mujer está levantando gran polvareda entre la mayoría de republicanos (...) Hubo un tiempo en que las feministas consultamos a algunos de los políticos que hoy actúan en el gobierno provisional, y

23. REIG, Ramir, Obrers i ciutadans. Blasquisme i moviment obrer, Valencia, 1982. Del mismo autor: Blasquistas y clericales, Valencia, 1986.

24. SANFEliU, Luz: Republicanas...

25. DASÍ ASENSI, Rosa, «La integración política de las mujeres valencianas: el P.U.R.A.», en Las mujeres y la guerra civil española, Madrid, 1992, pp. 74-79. 
nos contestaron que ese voto sería contraproducente para los ideales progresivos. Y casi nos convencimos: pero hoy con el advenimiento de la República hemos alcanzado el poder respirar un ambiente libre de atávicos prejuicios.

Razón es que llegue su hora a la mujer. No sólo corresponde en estos momentos ponerse al servicio de esta ley para allanar los obstáculos y preparar a la ciudadana de forma que comprenda lo que se va a poner en sus manos. No se trata de feministas y antifeministas; se trata sólo de aprovechar las fuerzas que pueda aportar la mujer $(\ldots) »^{26}$.

Es en este contexto en el que las mujeres republicanas vinculadas al PURA comenzaron durante la República a articular la sección femenina del partido, denominada Acción Femenina Republicana, que empezó a funcionar a partir del mismo mes de agosto de 1931. Se intentaba así encuadrar políticamente a las mujeres valencianas, para lo que el blasquismo contaría, por un lado, con las antiguas dirigentes laicistas, librepensadoras y sufragistas; y por otro lado, con la infraestructura organizativa de los casinos republicanos en los diferentes distritos y barrios de la ciudad de Valencia:

«Ciudadanas: esta agrupación, fundada por un grupo numeroso de republicanas consecuentes y admiradoras fervientes de Blasco Ibáñez, hace un llamamiento a todas las mujeres republicanas de Valencia y su provincia, y las invita a inscribirse en sus filas, para lo cual pueden dirigirse personalmente o por escrito a la calle Jesús, 4, bajo, todos los días de cuatro a ocho de la noche» ${ }^{27}$.

Las nuevas agrupaciones femeninas que se fueron creando se integraban en la Federación Central Femenina, dirigida por mujeres, pero bajo la «protección» del partido blasquista. La principal dirigente de esta Federación Central, Rosalía Figueras, fue una de las pocas mujeres republicanas que llegó a formar parte de la dirección del PURA.

El ámbito de expansión de las Agrupaciones Femeninas Republicanas se localizaba fundamentalmente en las zonas periféricas de la ciudad de Valencia, donde residían clases trabajadoras y pequeña burguesía urbana: principalmente, en los distritos de Hospital, Misericordia, Museo, Ruzafa, Vega y Puerto. El periódico El Pueblo, en su sección denominada Vida republicana, informaba regularmente sobre el número de agrupaciones que iban surgiendo, así como de las reuniones y actos que se realizaban, de tal manera que puede deducirse que a finales de 1933 el número de agrupaciones femeninas sería equivalente al número de casinos republicanos. La movilización política femenina fue desarrollándose así en Valencia a lo largo del período republicano,

26. Amalia Carvia, «Sobre el voto de la mujer», El Pueblo, 30-III-1932.

27. «Acción Femenina Republicana», El Pueblo, 14-VIII-1931. 
desde una estructura de partido organizada, y de sus prácticas políticas informaba también puntualmente El Pueblo:

«Ayer llegaron a Valencia cerca de doscientas mujeres pertenecientes a las agrupaciones femeninas que se desplazaron a Madrid para escuchar a Lerroux» ${ }^{28}$.

El debate ideológico y político que se produjo durante la República en torno a la aprobación de la ley de divorcio ${ }^{29}$ fue una de las cuestiones en las que las agrupaciones femeninas blasquistas se emplearon a fondo, defendiendo el divorcio como una necesidad democrática y como derivación de la consideración del matrimonio como un contrato disoluble. La apuesta por una sociedad laica, por la separación entre la Iglesia y el Estado, necesariamente se extendía a la redefinición del matrimonio y la posibilidad de divorcio, concretada en el artículo 43 de la Constitución de 1931, y sobre todo, en las leyes de divorcio de 2 marzo de 1932 y de matrimonio civil de 28 junio de 1932.

En el debate sobre el mismo las activistas de derechas y católicas desarrollaron una fuerte campaña demagógica, haciendo creer a las mujeres con escasos recursos culturales que el divorcio permitiría a los maridos abandonar su hogar en cuanto se les antojara, como recordaba Margarita Nelken en 1936 en su libro ¿Por qué hicimos la revolución? La prensa conservadora tronó contra la destrucción de la familia por el divorcio, y contra la «inaudita» pretensión de que el matrimonio fuese terreno del Estado y no de la Iglesia.

La campaña de desprestigio de la ley fue enormemente virulenta en Valencia, organizada por la Derecha Regional Valenciana, el partido católico y regionalista fundado por Luís Lucia en 1929, y de forma particular por su organización femenina, Acción Cívica de la Mujer (ACM), creada en noviembre de 1931 coincidiendo con la aprobación del texto constitucional. Las Agrupaciones Femeninas Republicanas respondieron a esta campaña en numerosos artículos publicados en El Pueblo, con palabras como éstas:

«Necios son los ataques dirigidos a la mujer republicana por las aguerridas y pintorescas huestes al servicio del cotidiano y obligado ágape de los ministros del altísimo. Lenguas viperinas desahogan el furor de sus femeninos y apergaminados pechos, insultando con furia fanática. Estas católicas cuando comienzan sus vituperios, se transfiguran tomando una maravillosa semejanza con la imagen del fanatismo $»^{30}$.

28. El Pueblo, 25-II-1932.

29. Aguado, Ana, «Entre lo público y lo privado...». También NúÑEz, Gloria, «Las consecuencias de la Segunda República: el triunfo parcial de la lógica de la igualdad», en 1898-1998. Un siglo avanzando hacia la igualdad de las mujeres, Madrid, 1999, pp. 139-208.

30. «La mujer», El Pueblo, 15-V-1932. 
Uno de los acontecimientos más relevantes, coincidente con la campaña electoral de 1933, fue el traslado a Valencia de los restos mortales de Blasco Ibáñez desde Menton, traslado que ha permanecido en la memoria de muchas mujeres y hombres valencianos que fueron testigos del mismo, y que lo vivieron como un gran acontecimiento. De su importancia simbólica da idea el hecho de que, desde el mes de agosto de 1931, las mujeres blasquistas se habían movilizado y habían comenzado a convocar reuniones "para tomar acuerdos sobre las medidas a tener en cuenta con la traída de los restos de Blasco Ibáñez» ${ }^{31}$. Iniciada la campaña electoral, cuando llegó el momento del traslado se celebraron en Valencia manifestaciones, que sirvieron de movilización electoral, a partir de los días 29 y 31 de octubre de 1933, con continuas actividades hasta el 5 de noviembre. Todas ellas estuvieron dirigidas por las Agrupaciones Femeninas Republicanas, y mostraron la fuerte capacidad de convocatoria que tenía el P.U.R.A. sobre las mujeres como nuevas electoras.

En la disputa de 1933 los republicanos ganaron las elecciones en los distritos electorales valencianos frente a la Derecha Regional Valenciana, a pesar del progresivo moderantismo de la dirección blasquista, cada vez más alejada de los sectores populares y de las clases trabajadoras valencianas que habían sido su principal base sociológica ${ }^{32}$. Tras las elecciones de noviembre, Lerroux -seguido por el PURA- pactaba con la CEDA y se iniciaba el gobierno de coalición radical-cedista. A partir de ese momento el PURA comenzó a desarticularse de forma que en 1935 el partido blasquista se había convertido sólo en una sombra política de lo que fue en el escenario político valenciano. Las Agrupaciones Femeninas republicanas acusaron también esta crisis interna. Resultaba difícil mantenerlas como un instrumento político electoral, pues habían ido adquiriendo conciencia política propia en tanto que ciudadanas, así como elementos discursivos políticamente autónomos, frente al viraje conservador que estaba experimentando el partido blasquista. No obstante, algunas agrupaciones femeninas se resistían a separarse del partido aunque le exigían respeto con relación a sus decisiones y posturas políticas:

«Vuelvo a repetir como condición indispensable de respeto mutuo y de disciplina a la jefatura del partido, que deben excluirse totalmente aquellas frases que puedan acusar o dar lugar a la más mínima sospecha de discrepancia entre sus miembros» ${ }^{33}$.

31. «Acción Femenina Republicana», El Pueblo, 12-VIII-1931.

32. FrANCH I FERRER, Vicent, El blasquisme. Reorganització i conflictos polítics (1929-1936), Xàtiva, 1983. Igualmente REIG, Ramir, Obrers i ciutadans....

33. Paula Cal y Lerroux, «Cultura Cívica Femenina», El Pueblo, 8-VIII-1934. 
Este proceso hacia una progresiva autonomía política y organizativa contaba con precedentes como la Unión Republicana Femenina, grupo republicano exclusivamente femenino dirigido por Clara Campoamor. En su manifiesto de 1932 Unión Republicana Femenina lamentaba la resistencia masculina a confraternizar con las mujeres en los partidos republicanos, así como el retraimiento de las mujeres para participar en la actividad política, y se planteaba como objetivos conseguir una mayor politización femenina, defender los derechos de las mujeres, y extender una cultura pacifista, identificándose con la tradicional vinculación entre pacifismo, feminismo y mujeres ${ }^{34}$.

\section{Cultura política e identidad de género en la formación de la Agrupación de Mujeres Antifascistas (AMA)}

En este contexto de crisis política y de tensión en las relaciones entre las mujeres y los partidos republicanos, paralela a la reorientación moderada del republicanismo blasquista valenciano, resulta de especial significación la organización en Valencia de la Agrupación de Mujeres Antifascistas. Porque la implantación de esta organización femenina de masas contó en Valencia con una parte de la militancia y con unas bases que se habían formado políticamente en las Agrupaciones Republicanas Femeninas ${ }^{35}$. Puede decirse así que existe una continuidad - una línea transversal- de desarrollo de una cultura femenina/feminista desde los republicanismos a las culturas políticas obreras que llegarán a su máxima extensión en la guerra civil. Línea que continuaría clandestinamente después de la guerra en la oposición política antifranquista.

En el contexto internacional de ascenso de los fascismos en la Europa del período de entreguerras, y particularmente, a partir de la llegada de Hitler al poder en 1933, mujeres de diferentes países vinculadas a partidos de izquierda, socialistas, comunistas o independientes, crearon Mujeres contra la Guerra y el Fascismo, tras la celebración del congreso de Amsterdam en el mes de agosto. En España se mantendría este nombre en el primer momento, entre 1933 y 1934. Tras pasar por un período de clandestinidad tras la represión de la revolución de octubre de 1934, período en el que adoptaría el nombre de Pro Infancia Obrera, en 1936 reapareció con el nombre de Agrupación de Mujeres Antifascistas (AMA), participando en la campaña electoral del Frente Popular. En ella se integraron mujeres de diferentes procedencias políticas, republicanas, socialistas y comunistas, aunque la dirección política

34. Fagoaga, Concha y SaAvedra, Paloma, Clara Campoamor. La sufragista española, Madrid, 1986. También FAGOAGA, Concha, La voz y el voto de las mujeres...

35. DASÍ ASENSI, Rosa, «La integración política de las mujeres valencianas...», p. 77. 
fue hegemonizada rápidamente por mujeres comunistas, con dirigentes como Dolores Ibárruri. Inicialmente, en su Comité Nacional se encontraban mujeres como Victoria Kent, Margarita Nelken, Federica Montseny o Clara Campoamor. La presidenta de honor era Catalina Salmerón, hija de Nicolás Salmerón, pero la presidenta efectiva era Dolores Ibárruri.

En 1934 se fueron creando numerosos comités femeninos de la organización, y poco después, dos delegadas de los comités formados en Madrid llegaron a Valencia y conectaron, clandestinamente, con aquellas mujeres que destacaban por su ideología izquierdista. Entre los contactos iniciales se encontraban Agustina Sánchez y Pilar Soler, simpatizantes comunistas, y éstas, a su vez, entraron en relación con los sectores femeninos que entonces estaban más politizados. Y los sectores femeninos más politizados en esos momentos eran las Agrupaciones Republicanas. Así lo expresaba Pilar Soler, que fue delegada provincial de Mujeres Antifascistas durante la Guerra Civil:

«Entonces, vimos que había que ir en busca de las mujeres. ¿Y donde estaban las mujeres? Y sobre todo, este tema de la lucha contra la guerra y el fascismo era para gente que ya tenía una formación política. De eso las mujeres valencianas de su casa no sabían nada, teníamos que ir a las mujeres que tenían una inquietud política (...). Entonces nos pusimos en contacto con las Agrupaciones Femeninas Republicanas, de las que yo ya conocía su existencia, y concretamente con una mujer, Carmen Manzana, que formaba parte de una agrupación de mujeres republicanas. Fue a través de Carmen Manzana que entramos en contacto con las Mujeres Republicanas» ${ }^{36}$.

Esta fue pues la vía por la que se organizó en Valencia la Agrupación de Mujeres Antifascistas, a partir de las mujeres que habían tenido una importante actividad política dentro de las Agrupaciones Femeninas Republicanas, y que habían comenzado a distanciarse del giro moderado, y de la línea oficialista que estaba desarrollando el PURA tras las elecciones de noviembre de 1933. Así, Carmen Manzana creó en el año 1934 el Comité Provincial de la Agrupación de Mujeres Antifascistas de Valencia, del que fue delegada. Asunción Chirivella, que había pertenecido a las Agrupaciones Femeninas Republicanas, fue delegada del mismo comité al comienzo de la guerra civil.

La implantación de la Agrupación de Mujeres Antifascistas en Valencia fue enormemente rápida entre 1934 y 1936, tanto en la ciudad como en pueblos cercanos, de tal manera que, comenzada la guerra, se convertiría en la organización de mujeres más importante de todo el territorio republicano. Este tránsito es clave para entender el proceso de politización femenina. La Agrupación de Mujeres Antifascistas se extendió en Valencia a partir de las Agrupaciones

36. Entrevista a Pilar Soler, 11-IV-2000. 
Femeninas Republicanas, que contaban con mujeres con una preparación política previa y con un alto nivel de politización. Las Agrupaciones Femeninas Republicanas de Valencia, herederas de la tradición de las librepensadoras y laicistas, vinculadas al blasquismo, sirvieron de base para la creación de la organización política femenina autónoma más importante cuantitativamente durante la Segunda República y la Guerra Civil: la Agrupación de Mujeres Antifascistas.

Estas formas semi-autonómas de organización política femenina se transformarían en un instrumento decisivo de movilización. Las mujeres, lejos de someterse a la dirección política blasquista, a partir de 1933 fueron tomando conciencia de su capacidad de autonomía, y de las posibilidades que el nuevo contexto político les ofrecía. En esta evolución ideológica, a partir del inicio de la Guerra Civil se desarrollaría, en el caso de las organizaciones como la Agrupación de Mujeres Antifascistas, una "conciencia femenina», -manteniendo el término de Temma Kaplan- cada vez más explícita y consolidada tanto en su lenguaje como en sus contenidos discursivos. Un planteamiento igualitarista en lo relativo a la participación activa de la mujer en la esfera públicopolítica, pero desde la reivindicación y la apelación a las funciones femeninas de cuidado y de defensa de la vida.

En este nuevo contexto, para las mujeres republicanas que conocían y trataban de difundir las vías políticas del feminismo extranjero, era claro que la política propia era también el camino para que la emancipación femenina se hiciera efectiva. La cultura política del republicanismo no basaba sus demandas, de una forma exclusiva, en la reivindicación de derechos individuales y subjetivos propia de la concepción liberal. La concepción republicana consideraba como función del Estado no sólo la protección de iguales derechos subjetivos privados, sino la garantía de un proceso de formación de la opinión y la voluntad política, en el que ciudadanos libres e iguales se entienden acerca de qué fines y normas redundan en interés común de todos ${ }^{37}$.

Estos procesos son los que confluyeron en España en la Segunda República, porque en contextos anteriores las mujeres no habían tenido posibilidad ni de proyectar su identidad relacionándola con sus principios ideológicos, ni de acceder a las representaciones o prácticas que el ejercicio de la política proporcionaba a los hombres. La vía principal a través de la cual los sujetos masculinos habían accedido a una subjetividad progresivamente individual y autónoma desde el inicio de la sociedad contemporánea y de los liberalismos,

37. HABERMAS, Jünger, «Tres modelos de democracia...», p. 19. 
el espacio público/político, el ejercicio práctico de las actividades políticas, había estado vetada con anterioridad, real y simbólicamente, a las mujeres.

\section{Conclusiones}

La experiencia y las identidades se conforman en un determinado contexto y desde unos determinados lenguajes. En el caso de las mujeres republicanas de los años treinta, en el contexto de la Segunda República y de los presupuestos igualitaristas de la cultura republicana. En este marco histórico podemos analizar las formas en que personas concretas han sido construidas como mujeres, cómo se ha modulado o elaborado su experiencia en función de un contexto preciso de posibilidades ${ }^{38}$. Con anterioridad a la Segunda República las mujeres no sólo habían carecido en momentos anteriores de derechos como el sufragio y la ciudadanía política, sino que, más aún, habían carecido de medios de integración de su «identidad» de una forma activa, y de instrumentos de socialización política ciudadana. Por tanto, carecían de «valor político», puesto que la falta de influencia electoral, además de impedirles decidir en la elección de los poderes públicos, también vaciaba de contenidos efectivos sus demandas y les privaba de unas prácticas de vida que las relacionasen directamente con la autonomía individual que, para los republicanos, constituía el origen y la fundamentación de la propia noción de ciudadanía. El acceso a esta ciudadanía contemplado en la Constitución de 1931 iba a ser la condición necesaria -no suficiente- para que las mujeres pudiesen obtener ese «valor político» autónomo e individual, pero al mismo tiempo, ese mismo acceso sería precisamente lo que posibilitaría el que las mujeres, a partir de ese momento, apelasen desde la cultura republicana a un «nosotras», a una identidad, con posibilidad de plantear demandas en el espacio público.

En el contexto de la España republicana se produjo política y jurídicamente la aparición de unas demandas identitarias de las mujeres como las «otras ciudadanas», -como «mujeres» y como «ciudadanas»-, desarrolladas a partir de su propia percepción de los discursos políticos universalistas. Así, puede decirse que esta «construcción» de las mujeres como tales -con una identidad específica- y como ciudadanas se produjo en, y desde, los referentes de culturas políticas universalistas como era en este caso el republicanismo como modelo político. También desde las culturas obreras, como el socialismo como cultura política igualitarista. Y a la vez, dentro del nuevo contexto político y legislativo que representó el régimen republicano entre 1931-1939,

38. HERNÁNDEZ SANDOICA, Elena, «Joan Scott y la historiografía actual», en BORDERÍAS, Cristina (ed.), Joan Scott y las políticas de la historia, Barcelona, 1996, p. 276. 
que permitió por primera vez en España el desarrollo de estas culturas con el acceso de las mujeres a la ciudadanía política.

Las mujeres que desde la cultura política republicana y socialista desarrollaron su activismo político durante la Segunda República, «ordenaron» a través del lenguaje las experiencias femeninas, tratando de construir una identidad común para un «sujeto histórico»-las mujeres-, cuya subjetividad social sólo en parte les era reconocida. En este sentido, y entendiendo que el feminismo proyectaba también discursivamente la construcción cultural de una identidad colectiva, podemos decir que, a través de los «lenguajes feministas» producidos por las mujeres desde la propia cultura republicana, éstas trataron de construir un «sujeto femenino», que tenía la necesidad no sólo de darse valor y reclamar los derechos sociales y políticos que les eran negados, sino también de formarse «un concepto especial del universo», una identidad. En el contexto histórico en que actuaban las republicanas, sólo el «homogeneizar» a las mujeres y dotarlas de una identidad colectiva daba ya posibilidades al feminismo para reclamar la emancipación femenina.

En este sentido, las reclamaciones de las republicanas relativas a derechos políticos apelaban por un lado al igualitarismo universalista, pero al mismo tiempo, reapropiándose en tanto que «mujeres» del sujeto político universal masculino del propio discurso republicano -Declaración de derechos del Hombre y del ciudadano-, apelaban igualmente una identidad femenina común, a un «nosotras»-Declaración de derechos de la Mujer y de la ciudadana-. Por ello es clave con relación a la construcción de las identidades de género, la significación que tuvo la adquisición de la ciudadanía política, igualdad política y civil ${ }^{39}$. En definitiva, la conciencia social, y más particularmente, la conciencia política de las mujeres, se conformaron en el seno de determinadas culturas políticas a partir de significados adquiridos, no sólo a través de mecanismos políticos formales, sino también a través de distintos mecanismos como las relaciones familiares, tradiciones culturales, solidaridades, espacios laborales, o roles sociales ${ }^{40}$. Es desde esas formas culturales desde las que se puede explicar el desarrollo de su conciencia política, tanto en clave de igualdad como en clave de diferencia. Las prácticas y las experiencias

39. NASH, Mary, «Dos décadas de historia de las mujeres en España: una reconsideración», Historia Social, no 9 (Invierno 1991), p. 152.

40. KAPLAN, Temma, «Conciencia femenina y acción colectiva: el caso de Barcelona, 19101918», en NASH, M. y Amelang, J. (ed.), Historia y Género: las mujeres en la Europa Moderna y Contemporánea, Valencia, 1990, pp. 267-295. 
políticas femeninas pueden vincularse a una cambiante conciencia práctica ${ }^{41}$, entendida no como un movimiento reivindicativo lineal, sino un proceso de aprendizaje desde diferentes referentes políticos, aprendizaje desde el cual pueden interpretarse y explicarse las formas de actuación política, de negociación o de estrategias desarrolladas por las mujeres ${ }^{42}$.

41. Llona, Miren, Entre señorita y garçonne. Historia oral de las mujeres bilbaínas de clase media (1919-1939), Málaga, 2002. Se ha reflexionado así recientemente desde el clásico y pionero planteamiento de WiLliams, Raymond, Marxismo y literatura, Barcelona, 1980, p. 58.

42. FRAISSE, Geneviève, Los dos gobiernos: la familia y la ciudad, Madrid, 2003. 